\title{
Formation of low-temperature self-organized nanoscale nickel metal islands
}

\author{
J D Carey, L L Ong and S R P Silva \\ Advanced Technology Institute, School of Electronics and Physical Sciences, \\ University of Surrey, Guildford GU2 7XH, UK \\ E-mail: David.Carey@surrey.ac.uk
}

Received 7 July 2003, in final form 3 September 2003

Published 7 October 2003

Online at stacks.iop.org/Nano/14/1223

\begin{abstract}
The growth and evolution of nanometre-sized Ni metal islands deposited under low-temperature non-ultra high vacuum conditions as a function of metal layer thickness, growth temperature and time is reported. The temperature of formation of the islands has been intentionally kept low for possible applications in flat panel display technology and also to act as a catalyst for carbon nanotube growth. It is shown that the size and distribution of the islands depends critically on the annealing temperature and the initial thickness of the metal layer. The mechanism of formation of the islands is described in terms of an Ostwald ripening mechanism of mass transport of either weakly bound individual $\mathrm{Ni}$ atoms or smaller clusters into larger more dispersed clusters.
\end{abstract}

\section{Introduction}

The study of the self-assembly of nanometre-sized metal and semiconductor islands has become particularly important recently as it is an attractive method for producing intrinsic nanoscale devices without the need for expensive lithography. Intrinsic limits imposed by the wavelength used in conventional deep-UV lithography make this technique unsuitable for nanoscale device fabrication. This leaves techniques based predominantly on direct writing with electron beams to define nanometre scale structures. Electron-beam techniques are expensive, time-consuming and generally have a lower throughput of devices. They also require the substrate to be conducting, which adds a further constraint to possible material systems that can be employed. By contrast, self-assembly on semiconductor surfaces is now well established, allowing the production of regular arrays of structures such as quantum wells, wires and dots [1]. Oxide-based nanostructures grown using self-organization have also been reported for a range of metals such as Pd, Ir, $\mathrm{Fe}$ and Co [2]. Nanometre-sized barrier-controlled devices which exhibit quantum conductance in metal-insulating-metal tunnel diodes have been fabricated through the use of current conditioning of metal oxides [3]. In addition, there has been considerable interest in using metals on oxides for applications in heterogeneous catalysis where the size distribution, shape and wetting properties of the metal overlayer are important. Most of the research in this area has largely proceeded in terms of monolayer and submonolayer deposition under ultra high vacuum (UHV) conditions, with particular emphasis on the electronic surface chemistry involved [4]. Metal-on-oxide deposition is now emerging in the field of large-area electronic applications that do not require UHV conditions and where it is important to know what is the most likely surface topology to be produced. This method is also able to produce such surfaces over large areas and, ideally, at low temperatures. Temperature considerations are important, since it is well known that heating deactivates many metal-on-oxide catalysts; surface reduction occurring after annealing under UHV conditions above $725 \mathrm{~K}$ has been reported [4].

One of the key aspects for technological applications is the need to be able to design the size and distribution of the nanoscale features that will be present. For example, it is advantageous to attempt to produce the same regular arrays of nanometre-sized transition metal (TM) islands which can then act as catalyst template sites for the growth of carbon nanotubes (CNTs) [5]; CNTs themselves have already been demonstrated to be efficient electron sources in flat panel displays [6]. However, to date most CNT growth has proceeded by making use of metal catalysts annealed 
at high temperatures or in the form of powders, making cleaning and adhesion to substrates problematic. Bower and co-workers [7] showed that thin films of sputtered cobalt could be used to produce metal islands to act as catalyst particles for CNT growth. In that study, the Co substrates were heated to $825^{\circ} \mathrm{C}$ for $\mathrm{CNT}$ growth. High-temperature $\left(725^{\circ} \mathrm{C}\right)$ treatment was also applied to magnetron sputtered $\mathrm{Ni}$ films by Chhowalla and co-workers [8]. In both these studies high temperatures were needed to facilitate the growth of the CNTs; however, a recent study has shown that carbon nanofibres, with a mean diameter of $45 \mathrm{~nm}$, can be grown at room temperature over large areas using 4-7 $\mu \mathrm{m}$ (grain size) Ni catalyst particles [9]. Growth has also been reported up to $250^{\circ} \mathrm{C}$, and in this temperature range nanometre-sized $\mathrm{Ni}$ acted as a catalyst in the 'tip growth' process. In this process the balance between $\mathrm{C}$ surface diffusion around the $\mathrm{Ni}$ particle and bulk diffusion through the particle is an important consideration [10]. Growth in both cases was by the liftingoff of the nanometre-sized Ni catalyst from the Ni particle in an rf plasma enhanced chemical vapour deposition (PECVD) system. Low-temperature growth of CNTs has also been recently reported using a dc PECVD system [11]. Nickel films of thickness $6 \mathrm{~nm}$, deposited using magnetron sputtering on a $\mathrm{SiO}_{2}$ substrate, were patterned using a transmission electron microscope grid as a shadow mask and also by using electron beam lithography. The former method produced large feature sizes $(\sim 10 \mu \mathrm{m})$ whereas $100 \mathrm{~nm}$ features were produced using electron-beam lithography. The two recent observations of growth at such low (macroscopic) temperatures points to the need for methodologies for the lower temperature formation of nanometre-sized $\mathrm{Ni}$ islands and an examination of their formation process without the need for complicated lithography or the problems associated with residual catalyst particles. The size of the resultant catalyst sites determines the growth properties of the CNTs themselves. An important consideration for a suitable catalysed substrate is the ability to scale up the catalyst templates to macroscopic dimensions to the requisite size for large-area applications, such as field emission displays (FEDs). With a FED application in mind, optimizing the growth of $\mathrm{Ni}$ island substrates is important for temperatures below $500{ }^{\circ} \mathrm{C}$ since it is above these temperatures that the glass used in conventional large-area displays begins to soften. The growth of these islands is not confined to acting as catalyst sites for the growth of CNTs alone; the natural protrusions themselves act as a substrate on which a cathode material may be deposited. The cathode material, such as an amorphous carbon thin film, will take the shape of the substrate and the size and shape of the islands can act as sources of geometric field enhancement allowing electron emission at low applied electric fields [12]. In this paper the growth of nanoscale $\mathrm{Ni}$ islands as a function of temperature and film thickness is reported under non-UHV conditions. We show that it is possible, by changing the metal layer thickness, temperature and growth time, to alter the diameter and separation between the islands.

\section{Experimental details}

Substrates of n-Si were initially cleaned using a standard three-stage ultrasonic solvent clean (acetone, methanol and isopropanol) and deionized water. A thin layer of $\mathrm{Ti}$ was evaporated on the substrates by heating Ti metal wire of known length in a suitable crucible in a vacuum of $5 \times 10^{-6} \mathrm{mbar}$. The films were then subsequently annealed for $30 \mathrm{~min}$ in air to form $\mathrm{TiO}_{2}$. Rutherford backscattering spectroscopy was used to confirm the composition of the film. The oxide thickness was measured by having previously masked off part of the substrate and monitoring it using atomic force microscopy (AFM). The AFM images of the surface were taken using an ambient Digital Instrument Nanoscope IIIa operating in tapping mode. Typical scan sizes were using a Digital Instrument $\mathrm{J}$ scanner were $4 \mu \mathrm{m} \times 4 \mu \mathrm{m}$. Ni films (whose thickness was determined by AFM) were then evaporated using high-purity Ni wire of known length and subsequently annealed under flowing $\mathrm{N}_{2}$ at temperatures from $300^{\circ} \mathrm{C}$ up to $500^{\circ} \mathrm{C}$ for times of 10,30 and $60 \mathrm{~min}$. It should be noted that the $\mathrm{Ti}$ and $\mathrm{Ni}$ evaporation times are not the same and the evaporations were performed for sufficient time to ensure that all the wire was used. The surface morphology of the films was monitored using the AFM. Statistical analysis of the resulting metal islands was performed using the associated AFM software. Care was taken to ensure that only clusters were included in the AFM analysis, using the methods available in the software.

\section{Results and discussion}

High-resolution AFM measurements of the unannealed $\mathrm{Ni}$ films with a thickness of $8 \mathrm{~nm}$ (not presented here) show the surface of the film to be extremely flat. In general, there are three ways in which metal films can grow on an oxide layer, the growth mechanism depending critically on the affinity of the metal to react with oxygen [13]. Metals which possess high heats of formation of the oxide react strongly with the substrate and produce flat 'wetting layers'. Further deposition of the metal results in 2D layer-by-layer growth (Frank-van der Merwe growth) (figure 1(a)) up until a critical thickness, beyond which it is favourable for the accumulated elastic strain in the metal film to be relaxed to form dislocations. However, the strain energy can be lowered at a lower film thickness through the formation of discrete 3D islands via the so-called Stranski-Krastanow (SK) growth mode (figure 1(b)). Weaker metal-substrate interactions are observed for the less reactive metals such as the noble metals. In this case wetting of the substrate does not take place and agglomeration of the metal into 3D islands immediately occurs (figure 1(c)). This is known as the Volmer-Weber growth mode [13]. The first row TMs bridge the gap between the strongly and weakly interacting metals with the metals to the left of iron being considered the 'more reactive' metals. The heats of formation of the oxide, $-\Delta H$, are $501 \mathrm{~kJ} \mathrm{~mol}^{-1}(\sim 5.2 \mathrm{eV})$ for Ti with $\mathrm{O}$ atoms, whereas that of $\mathrm{Ni}$ is $241 \mathrm{~kJ} \mathrm{~mol}^{-1}(\sim 2.49 \mathrm{eV})$ [12]. Since the value of $-\Delta H$ for $\mathrm{Ni}$ is about half that of $\mathrm{Ti}$ the growth of $\mathrm{Ni}$ on $\mathrm{TiO}_{2}$ will result in little interaction with the substrate. This weak interaction of the $\mathrm{Ni}$ with the oxide has a number of important consequences. The low value of $-\Delta H$ is important in determining if there will be a thin electron reduced surface layer. It is known that the thickness of a reduced $\mathrm{TiO}_{x}$ layer at the metal/ $/ \mathrm{TiO}_{2}$ interface decreases as the magnitude of the heat of formation decreases. Diebold and colleagues noted that $\sim 4$ monolayers (ML) of reduced $\mathrm{Ti}$ are found at 
Initial deposition
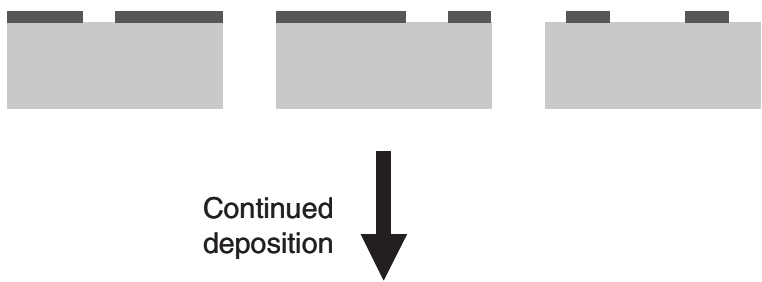

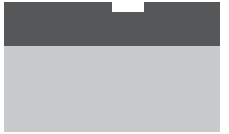

(a)

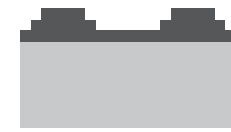

(b)

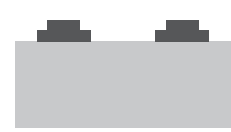

(c)
Figure 1. Schematic representation of the different metal-oxide growth modes showing initially wetting behaviour and subsequent metal deposition for: (a) 2D Frank-van der Merwe layer-by-layer growth, (b) SK growth mode with 3D island formation above a 2D layer beyond a critical layer thickness and (c) 2D Volmer-Weber growth mode with no wetting layer deposited.

the $\mathrm{Hf} / \mathrm{TiO}_{2}$ interface where $-\Delta H$ per metal-oxygen bond is $5.8 \mathrm{eV}$. This decreased to $\sim 1 \mathrm{ML}$ in the $\mathrm{Cr} / \mathrm{TiO}_{2}$ system $(-\Delta H=3.5 \mathrm{eV})$ and $0.4 \mathrm{ML}$ for $\mathrm{Fe} / \mathrm{TiO}_{2}(-\Delta H=2.8 \mathrm{eV})$. No reduced layer was observed in the $\mathrm{Cu} / \mathrm{TiO}_{2}$ system, for which $-\Delta H$ is $1.7 \mathrm{eV}$ [14]. Since the value of $-\Delta H$ for $\mathrm{Ni}$ is $2.49 \mathrm{eV}$, intermediate between $\mathrm{Cu}$ and $\mathrm{Fe}$, it is not expected that a significant reduced $\mathrm{TiO}_{x}$ layer will be formed. The study of Ni-based layers is therefore interesting in its own right since it is at the interface between the strongly and weakly reacting metals. Furthermore the properties of as-deposited metal overlayers are typically far from equilibrium and cannot be completely understood solely from thermodynamic factors. For example, the surface free energy of oxides is lower than that of metals, which would mean that all layers should form islands. Kinetic factors which affect mass transport and surface diffusion of material are therefore an important consideration.

In figure 2 the evolution of the surface morphology of a series of $\mathrm{Ni}$ films with an initial metal thickness of $8 \mathrm{~nm}$ annealed for $30 \mathrm{~min}$ as function of annealing temperature from 300 to $500{ }^{\circ} \mathrm{C}$ (table 1 , samples $1-3$ ) is shown. The morphology of the Ni film annealed at $300{ }^{\circ} \mathrm{C}$ (figure 2(a)) shows evidence for the formation of small closely packed islands with an average diameter of $80 \mathrm{~nm}$. On annealing at $400{ }^{\circ} \mathrm{C}$ the film morphology changes, with the formation of larger islands with a mean diameter of $114 \mathrm{~nm}$ coupled with a larger inter-island spacing. Finally, after annealing at $500^{\circ} \mathrm{C}$, large-diameter islands (average diameter of $306 \mathrm{~nm}$ and a standard deviation of $97 \mathrm{~nm}$ ) can be seen in figure 2(c). The resultant islands are also more isolated from each other. The results shown in figure 2 demonstrate that annealing at successively higher temperatures results in the formation of isolated large-diameter islands at the expense of smaller closepacked islands. Taking the room-temperature lattice constant of $\mathrm{Ni}$ to be $0.352 \mathrm{~nm}$ and that of the corresponding crystalline $\mathrm{TiO}_{2}$ surface to be $0.649 \mathrm{~nm}$ in the $a$ direction and $0.296 \mathrm{~nm}$ in the $c$ [001] direction [14] gives the room-temperature strains as $\varepsilon_{a}=-45 \%$ and $\varepsilon_{c}=+19 \%$ respectively. This means that the deposition of $\mathrm{Ni}$ on $\mathrm{TiO}_{2}$ results in a high degree of compressive strain in the $c$ direction and tensile strain in the $a$ direction. This
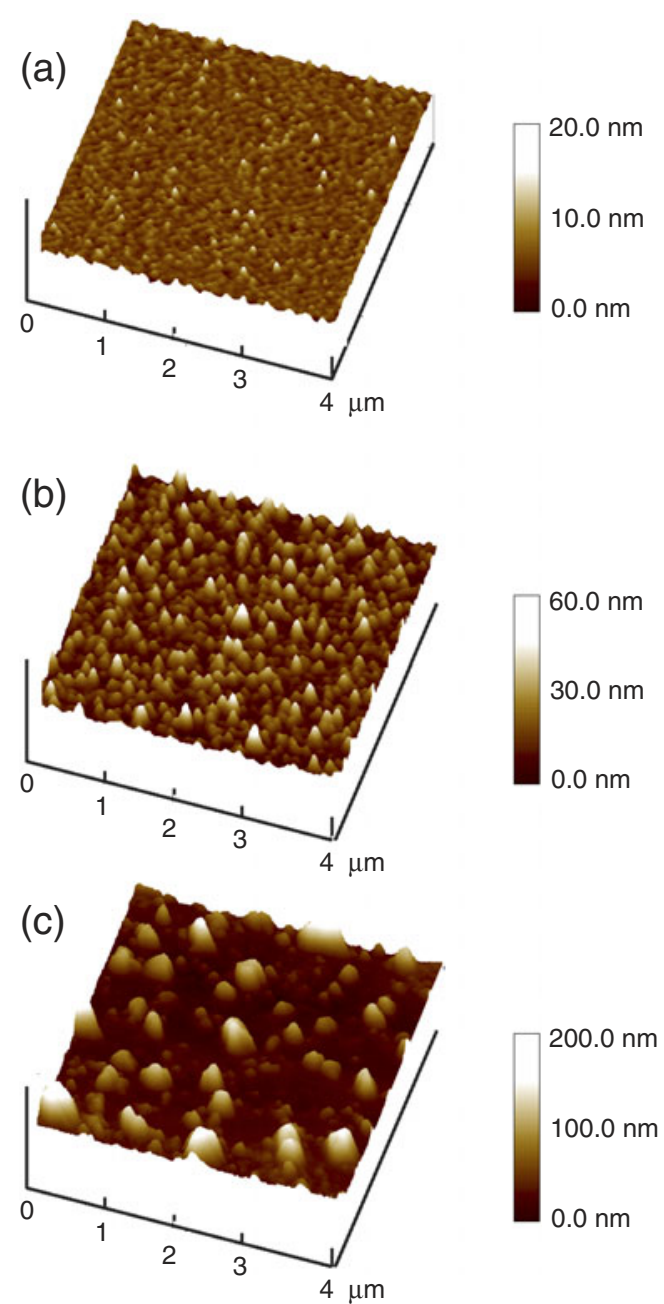

Figure 2. AFM images of $8 \mathrm{~nm}$ thickness of $\mathrm{Ni}$ evaporated films isochronally annealed for $30 \mathrm{~min}$ at (a) $300^{\circ} \mathrm{C}$, (b) $400^{\circ} \mathrm{C}$ and (c) $500^{\circ} \mathrm{C}$. Note the change in vertical scale between images.

strain energy is not substantially reduced since the coefficients of linear expansion [15] for $\mathrm{Ni}\left(13.4 \times 10^{-6} \mathrm{~K}^{-1}\right)$ and $\mathrm{TiO}_{2}$ $\left(7.14 \times 10^{-6} \mathrm{~K}^{-1}\right.$ in the $a$ direction and $9.19 \times 10^{-6} \mathrm{~K}^{-1}$ in the $c$ direction) are similar. The effect of annealing at high temperatures is to allow mass transport of either individual $\mathrm{Ni}$ atoms or small clusters across the surface in which larger clusters could be formed out of smaller clusters in a process analogous to Ostwald ripening. Evidence for the Ostwald ripening effect was also observed for $\mathrm{Cu}$ overlayers on $\mathrm{TiO}_{2}$, where it was also noted that the activation energy for diffusion of atoms would be of the order of 5-20\% of the binding energy of an atom to its surface. Since both $\mathrm{Ni}$ and $\mathrm{Cu}$ have low interactions with the $\mathrm{TiO}_{2}$ surface, as explained previously, low barriers for diffusion would be predicted [16]. In a study of $\mathrm{Cu}$ on $\mathrm{TiO}_{2}$ using X-ray photoemission spectroscopy [15], a value for the activation energy for diffusion of only $0.13 \mathrm{eV}$ was measured. The increase in the standard deviation of the cluster diameter (table 1) as a function of annealing temperature is also consistent with a surface diffusion mechanism, since the size of an island will depend on the ability of Ni to be locally gathered from one site to a growing cluster. Further confirmation of a surface diffusion hypothesis leading to larger islands can be found from examination of the island density presented in 
Table 1. Sample growth conditions and AFM characteristics.

\begin{tabular}{llllllll}
\hline Sample & $\begin{array}{l}\text { Initial Ni } \\
\text { thickness } \\
(\mathrm{nm})\end{array}$ & $\begin{array}{l}\text { Anneal } \\
\text { temperature } \\
\left({ }^{\circ} \mathrm{C}\right)\end{array}$ & $\begin{array}{l}\text { Anneal } \\
\text { time } \\
(\mathrm{min})\end{array}$ & $\begin{array}{l}\text { Mean } \\
\text { diameter } \\
(\mathrm{nm})\end{array}$ & $\begin{array}{l}\text { Standard } \\
\text { deviation } \\
(\mathrm{nm})\end{array}$ & $\begin{array}{l}\text { Island } \\
\text { density } \\
\left(\mu \mathrm{m}^{-2}\right)\end{array}$ & $\begin{array}{l}\text { AFM } \\
\text { image }\end{array}$ \\
\hline 1 & 8 & 300 & 30 & 80 & 51 & 32.6 & Figure 2(a) \\
2 & 8 & 400 & 30 & 114 & 67 & 15.6 & Figure 2(b) \\
3 & 8 & 500 & 30 & 306 & 97 & 2.3 & Figure 2(c) \\
4 & 3 & 400 & 30 & 67 & 40 & 27.2 & Figure 3(a) \\
5 & 5 & 400 & 30 & 89 & 72 & 22.4 & Figure 3(b) \\
6 & 5 & 400 & 10 & 71 & 57 & 36.6 & Figure 4(a) \\
7 & 5 & 400 & 60 & 85 & 61 & 25.8 & Figure 4(b) \\
\hline
\end{tabular}
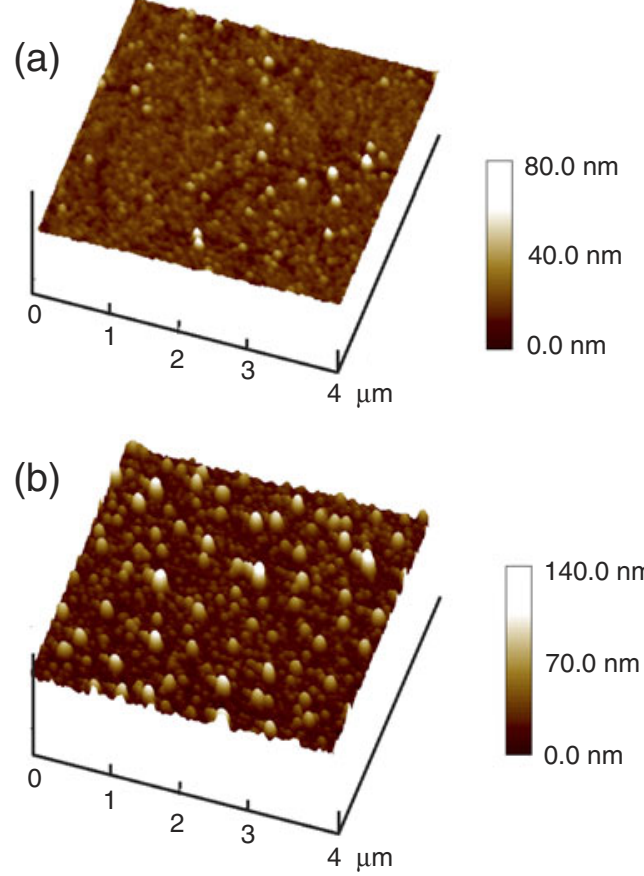

Figure 3. AFM images of (a) $3 \mathrm{~nm}$ and (b) $5 \mathrm{~nm} \mathrm{Ni}$ evaporated films isothermally annealed at $400{ }^{\circ} \mathrm{C}$ for $30 \mathrm{~min}$. Note the change in vertical scale between images.

table 1. On thermal annealing, the density of islands decreases from $32.6 \mu \mathrm{m}^{-2}$ at $300{ }^{\circ} \mathrm{C}$ (sample 1) by over an order of magnitude after annealing at $500{ }^{\circ} \mathrm{C}$ (sample 3 ).

It is known that the initial thickness of the metal film can play an important role in determining surface morphology at a given temperature [2,7]. We have examined the influence of using a smaller (less than $8 \mathrm{~nm}$ ) initial $\mathrm{Ni}$ thickness to investigate this effect. Figure 3 shows the surface morphology of two films (samples 4 and 5) annealed at $400{ }^{\circ} \mathrm{C}$ for $30 \mathrm{~min}$ having an initial Ni thickness of (a) $3 \mathrm{~nm}$ and (b) $5 \mathrm{~nm}$ respectively. From figure 3(a) it is apparent that there is some evidence of island growth for an initial Ni thickness of $3 \mathrm{~nm}$ with a mean diameter of $67 \mathrm{~nm}$. At a metal thickness of $5 \mathrm{~nm}$ larger islands (mean diameter $89 \mathrm{~nm}$ ) are formed, but this process is accompanied by an increase in the standard deviation of the island diameters.

Finally, we have also investigated the effects of different annealing times. The samples previously discussed were all annealed for $30 \mathrm{~min}$ at their respective temperatures and $\mathrm{Ni}$ layer thicknesses. For films with an Ni thickness of $5 \mathrm{~nm}$ we found that even after $10 \mathrm{~min}$ (sample 6) evidence of (a)

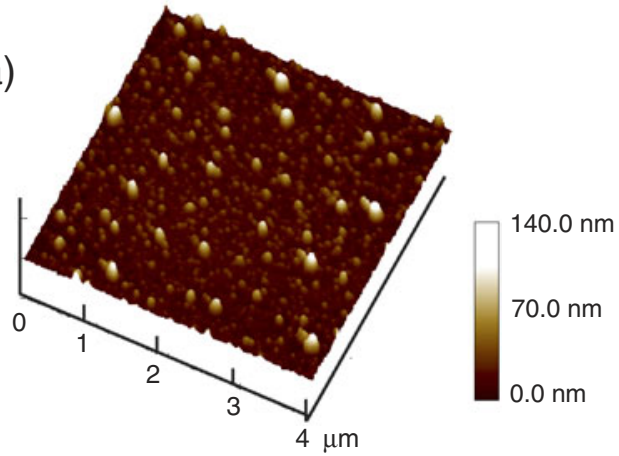

(b)

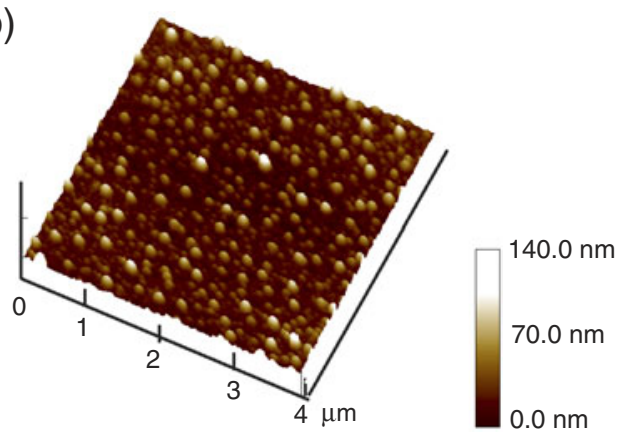

Figure 4. AFM images of a $5 \mathrm{~nm}$ Ni evaporated film annealed at $400^{\circ} \mathrm{C}$ for (a) $10 \mathrm{~min}$ and (b) $60 \mathrm{~min}$. The AFM image of the film annealed for $30 \mathrm{~min}$ has been presented in figure 3(b) and the same scale bar is used between the images.

island formation was present (figure 4(a)). Island coverage was improved after a $30 \mathrm{~min}$ anneal, as previously reported in figure 3(b) for sample 5. In the case of a $60 \mathrm{~min}$ anneal (sample 7) much more uniform island coverage can be seen, consistent with the mass transport Ostwald ripening mechanism discussed previously.

From these results we conclude that the two most important aspects in producing $\mathrm{Ni}$ islands are the annealing temperature and the initial Ni layer thickness. Annealing at higher temperatures produces larger-diameter islands which are further apart from one another. The weak interaction between the $\mathrm{Ni}$ and the oxide layer results in a low activation energy barrier to Ni migration which results in larger islands forming from smaller islands or weakly bound individual $\mathrm{Ni}$ atoms. As the Ni clusters get larger they become more dispersed which may be important in the growth of vertically aligned CNTs in which the presence of nearby tips can increase onset fields due to partial field screening [17]. A similar effect would also occur if the islands are templates for large-area field emission arrays. 
Formation of low-temperature self-organized nanoscale nickel metal islands

\section{Conclusion}

In conclusion, we have shown that it is possible to produce nanometre-sized $\mathrm{Ni}$ islands by choosing the correct initial $\mathrm{Ni}$ thickness, annealing temperature and annealing time. It is found that the two most crucial factors are the annealing temperature and the initial Ni thickness. For formation of closely spaced islands an optimum annealing temperature of $400^{\circ} \mathrm{C}$ was observed once the $\mathrm{Ni}$ thickness was $5 \mathrm{~nm}$ or above. For annealing at $500{ }^{\circ} \mathrm{C}$ coalescence of surface atoms through diffusion results in larger well-spaced islands. The mechanism for island growth and possible applications to large-area field emission arrays and catalyst sites for low-temperature CNT have been discussed.

\section{Acknowledgments}

JDC would like to acknowledge the EPSRC for the award of an Advanced Research Fellowship through grant GR/R76288. The authors would also like to thank Dr W T Young for performing the Rutherford backscattering spectroscopy measurements.

\section{References}

[1] Facsko S, Dekorsy T, Koerdt C, Trappe C, Kurz H, Vogt A and Hartnagel H L 1999 Science 2851551

[2] Aggarwal S, Ogale S B, Ganpule C S, Shinde S R,

Novikov V A, Monga A P, Burr M R, Ramesh R, Ballarotto V and Williams E D 2001 Appl. Phys. Lett. 78 1442
[3] Schmidt T, Martel R, Sandstrom R L and Avouris P 1998 Appl. Phys. Lett. 732173

[4] Tanner R E, Goldfarb I, Castell M R and Briggs G A D 2001 Surf. Sci. 486167

[5] Endo M, Takeuchi K, Kobori K, Takahashi K, Kroto H and Sarkar A 1995 Carbon 33873

[6] Choi W B, Chung D S, Kang J H, Kim H Y, Jin Y W, Han I T, Lee Y H, Jung J E, Lee N S, Park G S and Kim J M 1999 Appl. Phys. Lett. $\mathbf{7 5} 3129$

[7] Bower C, Zhou O, Zhu W, Werder D J and Jin S 2000 Appl. Phys. Lett. 772767

[8] Chhowalla M, Teo K B K, Ducati C, Rupesinghe N L, Amaratunga G A J, Ferrari A C, Roy D, Robertson J and Milne W I 2001 J. Appl. Phys. 905308

[9] Boskovic B O, Stolojan V, Khan R, Haq S and Silva S R P 2002 Nat. Mater. 1165

[10] Louchev O A, Sato Y and Kanda H 2002 Appl. Phys. Lett. 80 2752

[11] Hofmann S, Ducati C, Robertson J and Kleinsorge B 2003 Appl. Phys. Lett. 83135

[12] Carey J D, Forrest R D and Silva S R P 2001 Appl. Phys. Lett. $\mathbf{7 8} 2339$

[13] See, for example, Henrich V E and Cox P A 1994 The Surface Science of Metal Oxides (Cambridge: Cambridge University Press) chapter 5

[14] Diebold U, Pan J-M and Madey T E 1995 Surf. Sci. 331-333 845

[15] Kaye G W C and Laby T H 1993 Tables of Physical and Chemical Constants 15th edn (London: Longman)

[16] Diebold U, Pan J-M and Madey T E 1993 Phys. Rev. B 47 3868

[17] Nilsson L, Groening O, Emmernegger C, Kuettel O, Schaller E, Sclapbach L, Kind H, Bonard J-M and Kern K 2000 Appl. Phys. Lett. 762071 